\title{
A NEW ERA: INTEGRATING TODAY'S "NEXT GEN" RESEARCH TOOLS RAVEL AND CASETEXT IN THE LAW SCHOOL CLASSROOM
}

\author{
Katrina June Lee, Susan Azyndar, and Ingrid Mattson*
}

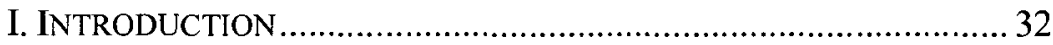

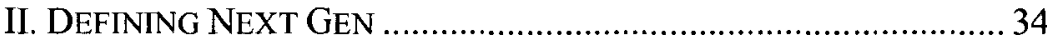

III. PEDAGOGY AND THE LATEST WAVE OF ElECTRONIC

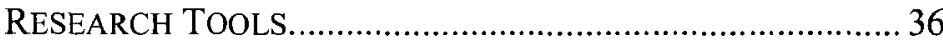

A. Calls for a More Practice-Focused Legal Education, and an Emphasis on Teaching Metacognitive Skills.... 40

B. The Goals of a Contemporary First-Year Legal

Research Curriculum................................................41

1. Information Literacy ................................................ 41

2. Ethical Use of Technology ...................................... 47

3. Varied Learning Styles............................................... 47

IV. PEDAgogy and CASETEXT AND RAVEL, Two of THE

NEW “NEXT GEN" RESEARCH TOOLS .................................. 48

A. Casetext: Resembling a Wikipedia for Case Law .......... 49

B. Ravel: A Picture is Worth a Thousand Words ... Or

Research Results ...................................................... 50

C. Legal Skills Pedagogy ..................................................... 53

1. Helping Students Become "Practice-Ready" ........... 54

2. Helping Students Develop Metacognitive Skills and Addressing Students' Varied Learning Styles

* Katrina June Lee is an Assistant Clinical Professor of Law, katrinalee@osu.edu, Susan Azyndar is a Reference Librarian and Adjunct Professor of Law, azyndar.1@osu.edu, and Ingrid Mattson is a Reference Librarian and Adjunct Professor of Law, mattson.30@osu.edu. All of the authors teach at The Ohio State University Moritz College of Law. The authors are grateful to Terri Enns, Catherine Lemmer, Anne Ralph, Sara Sampson, Mary Whisner, Jodi Wilson, and participants in the Moritz College of Law Clinical Brownbag session on July 29, 2014, for their comments. 
3. Enhancing the Teaching of Information

Literacy: Strategy, Context, and Source

Evaluation

V. TEACHING NeXt Gen RESEARCH TOOLS: A TEACHING

AND ASSESSMENT PILOT MODULE, AND IDEAS FOR

MOVING FORWARD

A. A Pilot Attempt at Teaching Next Gen Research

Tools

B. Takeaways and Ideas for Moving Forward with

Teaching "Next Gen" Research Tools

VI. CONCLUSION

\section{INTRODUCTION}

The landscape of legal research tools is changing ... again. In the not so distant past, law professors brought new research tools like WestlawNext, Lexis Advance, and Google Scholar into their classrooms. ' Now, in a technological blink of the eye, law professors must grapple with how to integrate the latest next generation ("next gen") research tools, including Ravel $^{2}$ and

1. WestlawNext debuted in 2011. Press Release, Thomson Reuters Unveils WestlawNext, the Next Generation in Legal Research, Pr Newswire (Feb. 1, 2010), $\mathrm{http}: / /$ www.prnewswire.com/news-releases/thomson-reuters-unveils-westlawnextthe-next-generation-in-legal-research-83240872.html. Lexis Advance was introduced in 2102. Press Release, Recently Launched Lexis Advance Features Next Generation Semantic Discovery Capabilities from $\mathrm{Net} O \mathrm{wl}$, LexisNexis

(Jan. 17, 2012), http://www.lexisnexis.com/en-us/about-us/media/pressrelease.page?id=132681445859947. Google Scholar began to offer case research in 2009. Brian D. Wassom, Is "Google Scholar" the Lexis/Westlaw-Killer?, LitiG. NEwS. (State Bar of Michigan, Lansing, Mich) (Winter 2010), 16, available at http://www.honigman.com/media/site_files/272_Google_20Article_20-

20Wassom.pdf. Law professors quickly began integrating the new tools and considering their impact on the classroom. See e.g., Eric P. Voigt, Interactive Ways to Teach Cost-Effective Research Using Google Scholar and LexisNexis, 19 L. TCHR. 41 (2012); Ronald E. Wheeler, Does WestlawNext Really Change Everything? The Implications of WestlawNext on Legal Research, 103 L. LIBR. J. 359 (2011).

2. Ravel debuted in 2012. About Us, RAVEL LAw, https://www.ravellaw.com/about (last visited Nov. 22, 2014). 
Casetext, ${ }^{3,4}$ in their classrooms. Should law professors teach these next gen research tools as part of the skills curriculum? If so, how?

In this article, we contend that law professors ${ }^{5}$ should integrate the new next gen research tools into the law school skills curriculum, and we propose a set of teaching ideas for doing so without sacrificing precious class time. Making the latest next gen research tools a part of the skills classroom agenda advances current pedagogical goals: teaching law students information literacy (e.g., research strategy, context, and source evaluation); ${ }^{6}$ teaching metacognitive skills, ${ }^{7}$ preparing students for law practice; ${ }^{8}$ and exploring professionalism and ethics issues. ${ }^{9}$ In Part II, we

3. Casetext debuted in 2013. Robert Ambrogi, New Legal Research Site Combines Case Law with Crowdsourcing, LAwSITES (July 26, 2013), http://www.lawsitesblog.com/2013/07/new-legal-research-site-combines-caselaw-with-crowdsourcing.html.

4. References to research tools are not meant as endorsements by the authors. Also, this article's observations regarding any research databases described herein reflect observations of database versions as of September 3, 2014.

5. Because research tools are most suited to courses that teach research skills-usually legal writing and research courses-much of this article focuses on legal skills courses. However, these research tools are useful even in doctrinal courses, as reflected in some of the exercises we propose in Part V.

6. Ellie Margolis \& Kristen E. Murray, Say Goodbye to the Books: Information Literacy as the New Legal Research Paradigm, 38 U. DAYTON L. REV. 117 (2012); Ellie Margolis \& Kristen Murray, Teaching Research Using an Information Literacy Paradigm, 22 Perspectives: Teaching Legal Res. \& WrITING 1, 8 (2014). See Part III below for more discussion.

7. See, e.g., Anthony S. Niedwiecki, Lawyers and Learning: A Metacognitive Approach to Legal Education, 13 WIDENER L. REv. 33, 33-34 (2006); Anthony Niedwiecki, Teaching For Lifelong Learning: Improving the Metacognitive Skills of Law Students Through More Effective Formative Assessment Techniques, 40 CAP. U. L. REv. 149, 157-59 (2012); Rosa Kim, Lightening the Cognitive Load: Maximizing Learning in the Legal Writing Classroom, 21 Perspectives: TEAching Legal Res. \& Writing 101, 104 (2013). See Part III below for more discussion.

8. See e.g., Suzanne J. Schmitz \& Alice M. Noble-Allgire, Reinvigorating the 1l Curriculum: Sequenced "Writing Across the Curriculum" Assignments As the Foundation for Producing Practice-Ready Law Graduates, 36 S. ILL. U. L.J. 287 (2012) ("Spurred in large part by the Carnegie Foundation's influential study of 2007 and its precursor, the American Bar Association's 'MacCrate Report,' law schools around the country have begun placing new emphasis on 'experiential learning' to prepare 'practice-ready' graduates."). See Part III below for more discussion.

9. See, e.g., Deborah L. Rhode, Legal Education: Rethinking the Problem, 
define "next gen" for purposes of this article. In Part III, we provide an overview of the pedagogical goals that form the major focus of recent literature about teaching legal skills. In Part IV, we give an overview of the newest next gen tools Ravel and Casetext and discuss how teaching these tools furthers those pedagogical goals. In Part V, we describe how, in our teaching and assessment pilot in a legal writing classroom, we introduced first-year law students to these tools. We provide post-exercise comments from students and offer ideas regarding how these tools may be integrated into future legal writing courses. In this article, the first to explore at length the teaching of the newest next gen research tools in the law school classroom, we aim to demonstrate that these tools provide an intriguing and exciting possibility for achieving the pedagogical goals of legal skills classrooms.

\section{DEFINING NEXT GEN}

By next generation, or next gen, research tools, we refer to an emerging group of legal research tools that include Ravel and Casetext. Introduced very recently, ${ }^{10}$ these tools represent a fundamental alteration in how legal research is presented online. They move far beyond merely providing a free alternative to subscription databases. ${ }^{11}$ Westlaw and Lexis have evolved their self-described next generation platforms in the past five years, ${ }^{12}$ and indisputably, WestlawNext and Lexis Advance introduced some innovation beyond adopting the Google-type search box. ${ }^{13}$ The new tools include, for example, useful graphic result charts

Reimagining the Reforms, 40 PEPP. L. REV. 437, 451 (2013). See Part III below for more discussion.

10. RAVEL LAW, supra note 2; Ambrogi, supra note 3.

11. Jean P. O'Grady, Ravel Law: Legal Research Radically Reimagined, DeWy B STRATEGIC (Aug. 27, 2014, 10:43 PM),

http://deweybstrategic.blogspot.com/2014/08/ravel-law-legal-research-

radically.html; Robert Ambrogi, 2 New Websites Offer Platform for Crowdsourced Legal Research, 100 ABA J. 28, 28 (Jan. 2014).

12. Thomson Reuters Unveils WestlawNext, the Next Generation in Legal Research, supra note 1; Recently Launched Lexis Advance Features Next Generation Semantic Discovery Capabilities from NetOwl, supra note 1.

13. E.g., Christine L. Sellers \& Phillip Gragg, Back and Forth ...WestlawNext and Lexis Advance, 104 L. LiBR. J. 341, 344 (2012). 
that graph the fate of a piece of litigation throughout our court system. ${ }^{14}$ A student pulling up a case in Lexis can use Shepard's Graphical, a tool that vaguely resembles a family tree, to see how the case has traveled through the appellate courts and where it reached final determination. ${ }^{15}$

Though these newer versions of conventional online legal research tools introduced features resembling the next gen tools themselves, the newer tools' primary functions addressed a refinement of how lawyers search rather than how they understand or visualize legal research results. ${ }^{16}$ At least a dozen new next gen legal research tools further pushing forward the evolution of legal research are in development. ${ }^{17}$ Two in particular-Casetext ${ }^{18}$ and Ravel ${ }^{19}$-have gained widespread attention from law and

14. Kim Ellenberg, WestlawNext Tip of the Week: Using Graphical KeyCite, THOMSON REUTERS, (June 18, 2012),

http://blog.legalsolutions.thomsonreuters.com/legal-research/reference-attorneytips/westlaw-next-tip-of-the-week-using-graphical-keycite/; Understanding the Graphs and Charts Used in LexisNexis ${ }^{*}$ Litigation Profile Suite, LEXISNEXIS.COM, http://help.lexisnexis.com/tabula-rasa/newlexis/lpsvsgraphs_ref-

reference?lbu $=$ US\&locale $=$

en_US\&audience=all,res,shep,Ipa,Ips,med,pub,vsa,lsa,cib,cb (last visited Nov. 26, 2014).

15. LexisAdvance Quick Reference: Research, LEXISNEXIS, 11 (2013), available at http://www.lexisnexis.com/pdf/LA_Quick_Reference_Guide.pdf.

16. However, some scholars have noted WestlawNext's possible effects on how lawyers understand results. See, e.g., Wheeler, supra note 1, at 368-69 (discussing potential "law changing effects" of WestlawNext including the limitation of creative thinking due to the erasure of obscure results); Melanie Knapp \& Rob Willey, Comparison of Research Speed and Accuracy Using Westlaw Classic and WestlawNext, 32 Legal ReferenCe SeRviCes Q. 126, 135137 (2013) (noting that WestlawNext uses terms and connectors differently from Westlaw Classic and the Google-equivalent giving users a potentially false impression of their results.)

17. ANGELLIST.CO, https://angel.co/legal (last visited Nov. 22, 2014) (providing a list of developing legal technologies seeking investors). AngelList.co helps entrepreneurs find investors; though not a comprehensive representation of all legal technologies under development, it does reflect market trends. See Daniel Martin Katz, Legal Tech Startups - \$458 Million in Legal Services R\&D (via TR Legal Executive Insights), Computational Legal Stud. (Feb. 11, 2014), http://computationallegalstudies.com/2014/02/11/legal-tech-startups-458-millionin-legal-services-rd-via-tr-legal-executive-insights/.

18. CASETEXT, www.castext.com (last visited Nov. 22, 2014).

19. RAVEL LAW, supra note 2. 
technology media groups. ${ }^{20}$ Described in greater detail in Part IV below, these two tools are in advanced beta ${ }^{21}$ development. Although both databases are limited in scope, ${ }^{22}$ the technology demonstrated by these tools has the potential to usher in a permanent change in online legal information databases. Accordingly, the authors chose Casetext and Ravel for their next gen research teaching pilot in the spring of $2014 .{ }^{23}$ We turn now to the pedagogical goals that informed our decision to initiate the teaching pilot.

\section{Pedagogy and the Latest Wave of Electronic RESEARCH TOOLS}

Both legal research and legal education seem to be in a state of

20. See, e.g., Ansel Halliburton, YC-Backed Casetext Takes a New Angle on Value Added Legal Research With Wikipedia-Style User Annotations, TECHCRUNCH (Aug. 12, 2013), http://techcrunch.com/2013/08/12/yc-backedcasetext-takes-a-new-angle-on-value-added-legal-research/; Robert Ambrogi, Crowd Searching: Collaborative Research is On Tap at 2 Sites, ABA J. (Jan. 1, 2014, 8:50 AM), available at http://www.abajournal.com/magazine/ article/2_new_websites_offer_platform_for_crowdsourced_legal_research/;

Haskell Murray, Casetext: Crowdsourcing and Legal Research, Bus. LAW PROF BLOG (Mar. 19, 2014), http://lawprofessors.typepad.com/business law/2014/03/ casetext-crowdsourcing-and-legal-research.html; Christina Farr, Ravel Raises $\$ 8 M$ to Help Lawyers Gather Data-and Cut Costs-in a New Way (Exclusive), VENTURE BEAT (Feb. 3, 2014, 12:20 AM), http://venturebeat.com/2014/02/03 /ravel-law-raises-8m-to-help-lawyers-gather-data-and-cut-costs-in-a-new-wayexclusive/; James E. McMillan, $Q \& A$ with Daniel Lewis of Ravel, COURT TECH. Bull. (Mar. 29, 2013), http://courttechbulletin.blogspot.com/2013/03/q-withdaniel-lewis-of-ravel-law.html.

21. The beta phase of development follows the alpha phase. In the alpha phase, a company tests its product in-house; in the beta phase, tests are conducted externally. In this phase, users may encounter bugs or other problems not yet corrected. David Noack, So You Wanna Be a Beta Tester?, 17 LiNk-Up 8 (Nov/Dec 2000).

22. See infra Part IV.

23. The legal research industry is currently in a state of extreme flux, so Ravel and Casetext may soon be followed by some newer "next gen" examples. This article's primary focus is on why new technologies (i.e., product features and functionality) rather than the new products themselves should be taught; thus we believe many of our observations and assertions apply to other emerging next gen products and their new product features. In other words, exposing students to new technologies in the form of Casetext and Ravel (in our case) can prepare them to teach themselves any newer products that come along. 
perpetual evolution. As research tools change, related pedagogical goals often do as well. In this Part, we will outline some of the changes in legal research tools and then explain how these changes have influenced pedagogy.

Law professors and legal researchers have responded to a sea change in electronic legal research in the past twenty years. Lexis and Westlaw terminals debuted in the $1970 \mathrm{~s},{ }^{24}$ but it was not until 1990 that students could access these databases from any computer. ${ }^{25}$ During the $1990 \mathrm{~s}$, electronic legal research began to take hold in the legal writing classroom. ${ }^{26}$ LexisNexis (purchased in the 1994 by Reed Elsevier ${ }^{27}$ ) and West Publishing (purchased in the 1996 by Thomson Reuters ${ }^{28}$ ) have dominated as legal research behemoths for many years. ${ }^{29}$ For a price, they both provided searchable electronic research databases (LexisNexis and Westlaw). ${ }^{30}$ The format and layout of these databases reflected for the most part the static, formal organizational system used in LexisNexis and West's print resources. For example, West replicated its famous key number system in Westlaw's case database, tagging each case with the pertinent key numbers. ${ }^{31}$ In other words, the electronic organizational system essentially

24. William G. Harrington, A Brief History of Computer-Assisted Legal Research, 77 L. LIBR. J. 543, 553 (1985) (Lexis was introduced in 1973, Westlaw in 1975).

25. Michael A. Geist, Where Can You Go Today?: The Computerization of Legal Education from Workbooks to the Web, 11 HARV. J. L. TECH. 141, 149 (1997).

26. See, e.g., Suzanne Ehrenberg, Legal Writing Unplugged: Evaluating the Role of Computer Technology in Legal Writing Pedagogy, 4 LEGAL WRITING: J. LEGAL WRITING INST. 1, 6-8 (1998), available at http://scholarship.kentlaw.iit.edu/fac_schol/778.

27. About LexisNexis, http://www.lexisnexis.com/about/ (last visited Nov. 22, 2014).

28. Mark J. McCabe, Merging West and Thomson: Pro- or AntiCompetitive?, 97 L. LIBR. J. 423, 423 (2005).

29. E.g., Olufunmilayo B. Arewa, Open Access in A Closed Universe: Lexis, Westlaw, Law Schools, and the Legal Information Market, 10 LEWIS \& CLARK L. REV. 797, 820-21 (2006).

30. Id.

31. See F. Allan Hanson, From Key Numbers to Keywords: How Automation Has Transformed the Law, 94 L. LiBR. J. 563, 575 (2002) (comparing the print and electronic key number systems). 
mirrored the print organizational system of the particular vendor. ${ }^{32}$

From the mid-1990s through 2010, the legal research world changed dramatically. New research tools sprang up, ${ }^{33}$ including Google, ${ }^{34}$ Google Scholar, ${ }^{35}$ and FindLaw. ${ }^{36}$ Government agency, court, and on-profit websites made statutes and regulations available. ${ }^{37}$ The new tools were often free and publicly available. ${ }^{38}$ Presentation to the user was streamlined. Less structure appeared

32. This is true regardless of whether the structure was apparent to those early users. See Barbara Bintliff, From Creativity to Computerese: Thinking Like a Lawyer in the Computer Age, 88 L. LIBR. J. 338, 341-42 (1996).

33. This list is far from exhaustive. Casemaker, Fastcase, and the Public Library of Law are among the many free and low cost legal research tools. For a list, see Timothy L. Coggins, Finding Legal, Factual, and Other Information in A Digital World, 18 Rich. J.L. \& TECH. 12, 6 (2012).

34. Google, www.google.com (last visited Nov. 22, 2014). Google grew out of a project Sergey Brin and Larry Page that began in 1996. Our History in Depth, GooGLE, http://www.google.com/intl/en/about/company/history/ (last visited Nov. $26,2014)$. Google is a search engine that "provides a list of links to websites, ordered in what Google deems to be of descending relevance to the user's search terms based on its proprietary algorithms." Rescuecom Corp. v. Google Inc., 562 F.3d 123, 125 (2d Cir. 2009).

35. GOOGLE SCHOLAR, www.scholar.google.com (last visited Nov. 22, 2014). In 2009, Google Scholar, a search engine limited to scholarly works, added a casesearching feature. Wassom, supra note 1, at 16. Coverage is limited to "US state appellate and Supreme Court cases since 1950, US federal district, appellate, tax and bankruptcy courts since 1923 and US Supreme Court cases since 1791." Search Tips, GOOGLE SCHOLAR, http://scholar.google.com/intl/en/scholar/ help.html\#coverage (last visited Nov. 22, 2014). For an assessment of the strengths and weaknesses of Google Scholar, see Alena Wolotira, Googling the Law: Apprising Students of the Benefits and Flaws of Google as a Legal Research Tool, 21 Perspectives: Teaching Legal Research \& Writing 33 (2012).

36. FindLAw, www. findlaw.com (last visited Nov. 22, 2014). FindLaw began in 1995. FindLaw Corporate Information Background: Company Background, FINDLAw, http://company.findlaw.com/company-history/findlawcorporate-information-press-company-background.html (last visited Nov. 22, 2014). FindLaw offers cases and statutes along with a wide range of other legal research material, such as blogs and a lawyer directory. FindLAw, About FindLaw, http://company.findlaw.com/ (last visited Nov. 22, 2014).

37. See e.g., Law and Regulations, FED. ELECTION COMM'N, http://www.fec.gov/law/law.shtml (last visited Nov. 22, 2014).

38. Jootaek Lee, Gatekeepers of Legal Information: Evaluating and Integrating Free Internet Legal Resources into the Classroom, 17 BARRY L. REV. 221, 222 (2012); Michael L. Rustad \& Diane D'Angelo, The Path of Internet Law: An Annotated Guide to Legal Landmarks, 2011 DuKE L. \& TECH. Rev. 12, 92 (2011). 
on the screen, and any organizational system was not readily visible to the user. Some of these research tools even began to incorporate a Web 2.0 mindset; for example, Cornell University developed Wex, a legal encyclopedia and dictionary with usergenerated content. ${ }^{39}$

In short, these tools disrupted the status quo of the legal research world and led to much reflection and to new ideas about teaching legal research. ${ }^{40}$ Thus, today, law school professors have the luxury of the extensive legal research and writing pedagogy scholarship developed over the past decade surrounding the teaching of Google and other new search tools. ${ }^{41}$ A concern emerged: while these new tools made research superficially quicker and easier, students were not necessarily becoming better researchers and perhaps were even becoming poorer researchers. ${ }^{42}$ Although students enter law school with experience using free online sources-perhaps most notably Google-legal employers still voice frustration that these students enter the workplaces with inadequate research skills. ${ }^{43}$ So, while

39. LEGAL INFO. INST., http://www.law.cornell.edu/wex (last visited Nov. 26, 2014) (only invited legal experts contribute to this site); see also John Cannan, In Search of Web 2.0, 12 AALL SPECTRUM 16, 18-19 (2007-2008).

40. See, e.g., Suzanne Ehrenberg, Legal Writing Unplugged: Evaluating the Role of Computer Technology in Legal Writing Pedagogy, 4 LEGAL WRITING: J. Legal Writing InST. 1 (1998); Kristin B. Gerdy, Jane H. Wise, \& Alison Craig, Expanding Our Classroom Walls: Enhancing Teaching and Learning Through Technology, 2 Legal Writing: J. Legal WRITING InST. 263 (2005); DaVID ThOMSON, LAw SChoOl 2.0: Legal Education For a Digital Age (2009).

41. Cindy Guyer, Experiential Learning: Context and Connections for Legal Research - A Case Study, 32 Legal ReferenCE SERvices Q. 161, 163-164 (2013).

42. See Stefan H. Krieger \& Katrina Fischer Kuh, Accessing Law: An Empirical Study Exploring the Influence of Legal Research Medium, 16 VAND. J. ENT. \& TECH. L. 757, 787-790 (2014); Lee F. Peoples, Testing the Limits of WestlawNext, 31 Legal REFERENCE SERVICES Q. 125, 139-40, 154 (2012).

43. Similarly, Ezster Hargittai has shown that college students who are "digital natives" do not all use the Internet at the same level of skill. Ezster Hargittai, Digital Na(t)ives? Variation in Internet Skills and Uses among Members of the "Net Generation," 80 Soc. INQUIRY 92 (2010).

Those who are already more privileged tend to have more Internet use autonomy and resources, more online experiences, higher levels of know-how and report engaging in more diverse types of uses than the less privileged, precisely the group that would stand a better chance of benefitting from these activities if they were more engaged with them.

Id. at 109 . The legal literature reveals a similar concern about the limitation of millennials in online searching. See Kris Gilliland, A Motivational Perspective on 
millennial students are very familiar with using the Internet for all kinds of activities, the effective use of online legal research tools requires instruction tailored to the nature of these new tools.

\section{A. Calls for a More Practice-Focused Legal Education, and an} Emphasis on Teaching Metacognitive Skills

While legal research tools evolved, legal educators were called on to develop and engage in best practices to prepare students for legal practice. Experiential learning and practical skills acquisition were emphasized in various reports, perhaps most prominently in the Carnegie Report. ${ }^{44}$ The Carnegie and MacCrate Reports both emphasized the need for legal education to embrace a wide range of lawyering skills. ${ }^{45}$

First-Year Legal Research Instruction, 28 Legal RefERENCE SERVices Q. 63, 64 (2009) (noting a mismatch between law students confidence and competency in research skills) (citing Ian Gallagher, '“Who Are Those Guys?': The Results of a Survey Studying the Information Literacy of Incoming Law Students, 44 CAL. W.L. Rev. 151 (2007)). See also Jeanne Eicks, Educating Superior Legal Professionals: Successful Modern Curricula Join Law and Technology, EduCATING THE DigiTal LAWYER § 5.D1 (Oliver Goodenough \& Marc Lauritsen, eds., 2012) ("Generally incoming students have high level consumer technical skills and low level professional technical skills.... Consumer technical knowledge consists of activities such as learning to play Wii or send a text message on a mobile phone. Learning how to use word processing software, a spreadsheet, digital shredding programs or case management software are examples of professional technical knowledge.").

44. See, e.g., William M. Sullivan ET al., Educating Lawyers: Preparation for the Profession of LaW 3-11 (2007) [hereinafter Carnegie Report]; Task Force on Law Sch. \& THE Profession: Narrowing the GaP, Am. BAR Ass'n SECTION OF Legal Educ. \& Admissions to THE Bar (Robert MacCrate et al. eds., 1992) [hereinafter MacCrate Report]; RoY STUCKEY ET AL., Best Practices for Legal. Education: A Vision and a Roadmap 7-9 (2007). The MacCrate Report specifically lists legal research as a fundamental lawyering skill, including in its description of this skill the need to address costs and time constraints. MacCrate Report at 157-163. While the Carnegie Report did not explicitly address legal research, it "has nevertheless influenced information literacy in legal education," a topic addressed below. Nancy B. Talley, Are You Doing it Backward? Improving Information Literacy Instruction Using the AALL Principles and Standards for Legal Research Competency, Taxonomies, and Backward Design, 106 L. LiBraRY J. 47, 52 (2014).

45. MacCrate Report, supra note 44, at 330-34; Carnegie Report, supra note 44 , at $10-11$. 
Law school professors answered this call. They produced pedagogical scholarship ${ }^{46}$ devoted to learning theory. Specifically, legal scholars focused on the concept of metacognition, i.e., a person's self-monitoring of his own cognitive processes. ${ }^{47}$ They advocated for developing strategies to help students become selfregulated learners, ${ }^{48}$ especially with respect to legal research. As discussed in the following Part, teaching legal research could not merely be a linear exercise of showing students how to click on $\mathrm{A}$ to get to B. Practical considerations demand more. The research tools students use in law school may not be available in their legal workplaces, whether for cost reasons or because the resources have changed dramatically or disappeared. Self-regulated learning will help students apply their research skills in this changing environment. To equip the student with the metacognitive and practice-based skills needed for a successful legal career, law teachers needed to be nimble and focus on a host of interrelated dynamic pedagogical goals.

\section{B. The Goals of a Contemporary First-Year Legal Research Curriculum}

\section{Information Literacy}

Scholars addressing the prior wave of electronic research tools, like FindLaw and Google Scholar, raised concerns primarily about

46. See Selected Bibliography on Legal Writing Pedagogy, CUNY SCHOOL OF LAW, http://www.law.cuny.edu/legal-writing/faculty/

pedagogy-bibliography.html\#wri (last visited Nov. 22, 2014).

47. See, e.g., Niedwiecki, Lawyers and Learning, supra note 7, at 33-35; Niedwiecki, Teaching For Lifelong Learning, supra note 7, at 157-59; Rosa Kim, Lightening the Cognitive Load: Maximizing Learning in the Legal Writing Classroom, 21 Perspectives: Teaching Legal Res. \& Writing 101, 104 (2013); Shailini Jandial George, Teaching the Smartphone Generation: How Cognitive Science Can Improve Learning in Law School, 66 ME. L. REv. 163, 179-182 (2013). Non-law scholars have of course also contributed significantly to this field. See, e.g., Christine S. Bruce, Hilary E. Hughes \& Mary M. Somerville, Supporting Informed Learners in the 21st Century, 60 LIBR. TRENDS 522 (2012).

48. See, e.g., Niedwiecki, Lawyers and Learning, supra note 7, at 33-34; Gilliland, supra note 43, at 66; George, supra note 47, at 181. 
three research skills: strategy, context, and source evaluation. These skills comprise information literacy. ${ }^{49}$ Teaching each of these information literacy skills helps make legal research teaching more practice-oriented and better aimed at developing a student's metacognitive skills ${ }^{50}$ or "awareness and control over one's own thinking."

\section{Strategy}

Legal research scholars have discovered students have no formal strategy when using readily available electronic search tools like Google. Many students turn to sites like Google and Wikipedia because they see these resources as "the easiest option." 52 Yet, a recent study found that only 36 percent of students developed a list of search terms, suggesting little attention to planning. ${ }^{53}$ So, law school professors must teach students "to design and implement a

49. "Information literacy is a set of abilities requiring individuals to 'recognize when information is needed and have the ability to locate, evaluate, and use effectively the needed information." Information Literacy Competency Standards for Higher Education, Ass'N OF COLL. \& RES. LIBRS. (2000), http://www.ala.org/acrl/standards/informationliteracycompetency\#fl (quoting AM. Libr. Ass'N, Presidential Committee on InFormation Literacy (1989)).

50. See Margolis \& Murray, Teaching Research Using an Information Literacy Paradigm, supra note 6; Phebe E. Poydras, Developing Legal Information Literate Law Students: "That Dog Will Hunt," 32 LEGAL ReFERENCE Services Q. 183, 187 (2013); Nancy B. Talley, Are You Doing it Backward?, supra note 44. The American Association of Law Libraries explicitly recognizes the importance of the information-literate law students. Principles and Standards for Legal Research Competency, AM. Ass'N L. LiBRS., http://www.aallnet.org /Documents/Leadership-Governance/Policies/policy-legalrescompetencybody.pdf (last visited Nov. 22, 2014). This description also comports with the Boulder Statement on Legal Research Education. Conference on Legal Information: Scholarship and Teaching, Boulder Statement on Legal Research Education, https://www.utexas.edu/law/faculty/pubs/bb26663_pub.pdf (last visited Nov. 22, 2014).

51. Niedwiecki, Lawyers and Learning, supra note 7, at 41 (offering a description of metacognition and importance to the learning process in law schools).

52. Aliza B. Kaplan \& Kathleen Darvil, Think [and Practice] Like a Lawyer: Legal Research for the New Millennials, 8 J. Ass'N Legal WriTING DiReCtors $153,166(2011)$.

53. Id. at 165 . 
research plan, ${ }^{, 54}$ both to use the free resources more effectively and to maximize the combination of free, paid, print, and electronic materials. In short, teaching legal research consists of providing guidance on when and why to consider using a given source, free or not. ${ }^{55}$

One study showed that "newly minted lawyers are even less likely than experienced attorneys to use free online research sources," at least in part because students do not receive a bill for these searches, heightening the need to explore these resources in the law classroom..$^{56}$ Thus, while students will often turn to Google and Wikipedia because it is the easiest option, after three years of law school with Westlaw and Lexis, they may enter the legal profession entrenched in the habit of limiting themselves to the feebased major online research databases. Without guidance from law school professors, they may overlook the advantages of strategizing about all legal databases for greatest efficiency, ignore entirely the wealth of free research options, and rely on slapdash search techniques regardless of the chosen database.

Free resources like Google Scholar avoid the fees subscription databases charge, but database fees are only one aspect of research

54. Id. at 185 .

55. Carrie W. Teitcher, Rebooting the Approach to Teaching Research: Embracing the Computer Age, 99 L. LIBR. J. 555, 565 (2007).

56. Sanford N. Greenberg, Legal Research Training: Preparing Students for a Rapidly Changing Research Environment, 13 LEGAL WRITING: J. LEGAL Writing INST. 214, 266 (2007); Jill L. K. Brooks, Great Expectations: New Associates' Research Skills from Law School to Law Firm, 28 LEGAL REFERENCE SERVICES Q. 291, 298 (2009) (advocating that new associates must have "knowledge of comprehensive free Web sites to find legal information"). But cf. Joseph D. Lawson, What About the Majority?

Considering the Legal Research Practices of Solo and Small Firm Attorneys, http://works.bepress.com/cgi/viewcontent.cgi?article=1097\& context=aallcall forpa pers (2014). Mr. Lawson surveyed local practitioners. Of the eighty-seven survey respondents, over eighty percent reported working as solo practitioners or in firms comprised of two-to-five attorneys. Forty-two percent of the total (87) survey respondents report they never or rarely use fee-based resources like Westlaw or Lexis, suggesting many in small firms rely on free research tools. Notably, the "free, online resources" the author asked about combined Google and Casemaker. Given the current job market and an increased likelihood new lawyers will enter into solo or small firm practice, the need for exposure to these free, next gen, legal research tools (as compared with general online search tools like Wikipedia and Google) is even more crucial. 
expense. ${ }^{57}$ The attorney's time spent researching is another substantial component of research expense for a client, and time spent researching can add up. Students need to be made aware of both aspects of cost. For example, in some situations, an attorney might save the client more money by using a combination of free and paid database resources than by using only free database resources. As an example of addressing this issue in the classroom, in 2011, one author suggested that students use Google Scholar to find a case and then update that case in a subscription database, "considering the purpose" of the research and "determin[ing] the quickest, least expensive, and most reliable way" to conduct it. ${ }^{58}$

Teaching students to strategize about the efficient use of various research resources was not a new goal. During the transition from a world comprised solely of print sources to one that includes electronic sources, instructors included in their classes information on the benefits and drawbacks of both print and electronic source research and the need for evaluation strategies. ${ }^{59}$

\section{Context}

The new online legal research tools also require students to do more to identify the relevant legal context. After all, legal analysis is highly context-driven. Barbara Bintliff describes the common context of law, in particular the hierarchical concepts that appear in the West digest system and in legal textbooks, as critical to communication about the law. ${ }^{60}$ Online sources arguably take no part in this hierarchy, and therefore do not support a shared context or meaning. ${ }^{61}$ For example, researchers can simply enter any term

57. E.g., Yasmin Sokkar Harker, "Information Is Cheap, but Meaning Is Expensive": Building Analytical Skill into Legal Research Instruction, 105 L. LIBR. J. 79, 82 (2013) ("lack of legal research skills is costly, both in terms of attorney time and in terms of commercial database charges.").

58. Susan W. Wawrose, What Do Legal Employers Want to See in New Graduates?: Using Focus Groups to Find Out, 39 OHIO N.U.L. REv. 505, 552 (2011).

59. See, e.g., Greenberg, supra note 56, at 267.

60. Barbara Bintliff, Context and Legal Research, 99 L. LiBr. J. 249, 251 (2007).

61. Id. at 259. See also Krieger supra note 42 (presenting an empirical study 
in a search box, without regard to a source's structure. ${ }^{62}$ Legal analysis can suffer as a result. For example, students may miss useful analogies if relying exclusively on free online sources. ${ }^{63}$

Educational theory and cognitive psychology confirm this phenomenon. Students must learn how to link concepts they have already learned to new contexts, which requires "recognizing that existing skills apply in a new situation, recalling those skills, and then judging how to use them appropriately for the change in circumstances." 64 Teachers must help students recognize cues signaling that even though the context has changed, "the new conditions are sufficiently similar that the previous skills should apply." 65

Those who teach legal writing discuss the universality of the legal research process: spotting the issue, brainstorming key search terms, understanding the areas of law implicated, and looking at secondary sources. ${ }^{66}$ Teaching students a fixed research process is one way to help them navigate ever-shifting research contexts. That is, a formal process is one way to ensure thorough, thoughtful research results regardless of whether the research is conducted online, in print, or both.

showing "electronic researchers can, in fact, be expected to emphasize fact terms" rather than legal concepts).

62. Id.

63. Kaplan, supra note 52, at 160.

64. Tonya Kowalski, Toward a Pedagogy for Teaching Legal Writing in Law School Clinics, 17 Clinical L. REV. 285, 291 (2010).

65. Id.

66. The time-honored Rombauer method of legal research includes these steps. Marjorie Dick Rombauer, Legal Analysis and Research (1970). In addition to subsequent editions of Rombauer's text, many more recent legal research textbooks recommend this approach. See, e.g., Amy SloAn, BASIC LEgAL Research: ToOls AND Strategies 14 (5th ed. 2012). Similarly, Knotts and Armstrong emphasize the need to develop a research plan, emphasizing the elements of historical background, legal authorities, and interpretations of those authorities. J.D.S. ARMSTRONG \& ChRISTOPHER A. KNOTT, WhERE THE LAW IS: AN INTRODUCTION TO ADVANCED LEGAL RESEARCH 1-12 (2004). Recent scholarship also supports a focus on the process of legal research. Nancy P. Johnson, Best Practices: What First-Year Law Students Should Learn in a Legal Research Class, 28 LEGAL REFERENCE SERVICES Q. 77, 79 (2009). 


\section{Source Evaluation}

Even if students execute a reasoned plan and recognize key legal concepts, they still need to evaluate their results. Subscription databases often perform this task for the researcher-editors select material included and provide ways of recognizing relationships between sources. ${ }^{67}$ Even there, however, some evaluation is necessary-not all secondary sources provide the same quality of content for a given research need. ${ }^{68}$

In the world of free online research, evaluation becomes even more necessary ${ }^{69}$ Searchers, particularly novice ones, often end up with a very large body of results, many irrelevant or inadequate from a legal perspective. ${ }^{70}$ As a result, a number of scholars urge instructors to emphasize evaluation. ${ }^{71}$ Students and lawyers alike need to understand which sources supply official authenticated sources of law and need to corroborate what they learn through free online research. ${ }^{72}$

Identifying and locating sources can be a very different task from evaluating sources. Scholars advocate teaching analysis or evaluation of research results in addition to their identification and retrieval. Ellie Margolis and Kristen E. Murray prioritize evaluation over strategy, ${ }^{73}$ proposing a "fluid and non-linear" approach to

67. See Bintliff, supra note 32 .

68. For a description of various secondary sources, explaining their different uses, see Lisa Smith-Butler, Cost Effective Legal Research Redux: How to Avoid Becoming the Accidental Tourist, Lost in Cyberspace, 9 Fla. COASTAL L. ReV. 293, 328-344 (2008).

69. See, e.g., Greenberg, supra note 56 , at 267 . We use "source evaluation" to refer to trustworthiness, authoritativeness, and relevance rather than the accuracy of the representation of a case on a particular database.

70. Ian Gallacher, Forty-Two: The Hitchhiker's Guide to Teaching Legal Research to the Google Generation, 39 AKRON L. REV. 151, 160-61, 184 (2006).

71. E.g., Margolis \& Murray, Say Goodbye to the Books, supra note 6, at 119 ("Legal research has shifted from a focus on how to find materials to careful evaluation of the wealth of information each search yields."); Kaplan \& Darvil, supra note 52, at 177 (claiming that "evaluate the diversity of information types" is an "essential skill" for law practice).

72. Kaplan, supra note 52, at 186.

73. Margolis \& Murray, Say Goodbye to the Books, supra note 6; Margolis \& Murray, Teaching Research Using an Information Literacy Paradigm, supra note 6 , at 8 . 
legal research. ${ }^{74}$ They posit a dichotomy between finding sources and evaluating them. While legal research and its instruction has traditionally focused on locating materials, that "is no longer the chief challenge," 75 especially in light of the plethora of free materials.

\section{Ethical Use of Technology}

As lawyers increasingly rely on technology for a variety of tasks, from research to client communication, bar associations face novel ethical questions. The American Bar Association recently adopted a change to Model Rule 1.1, requiring lawyers to "keep abreast of changes in the law and its practice, including the benefits and risks associated with relevant technology." " Law professors strive to raise students' awareness of professionalism, including attention to legal ethics. ${ }^{77}$ Through legal writing assignments, law students can begin to explore technology and think about potential problems whether related to recovering costs from clients, exposing confidential information via social media, or conducting comprehensive, accurate online legal research.

\section{Varied Learning Styles}

Against the backdrop of these broad pedagogical goals, legal educators also sought to meet students' varied learning styles and

74. Margolis \& Murray, Say Goodbye to the Books, supra note 6, at 152.

75. Id. at 119 .

76. Model Rules of Prof'l Conduct R. $1.1 \mathrm{cmt}$. (8) (2012).

77. See, e.g., Margaret Z. Johns, Teaching Professional Responsibility and Professionalism in Legal Writing, 40 J. LEGAL EdUC. 501, 502-503 (1990). Legal writing professors already use their classes as an occasion to educate students on attorney ethics, so educating students on using technology ethically should be no great stretch. See, e.g., Kristen E. Murray, Legal Writing Missteps: Ethics and Professionalism in the First Year Legal Research and Writing Classroom, 20 Perspectives: Teaching Legal Res. \& Writing 134, 135 (2012); Wayne Schiess, Ethical Legal Writing, 21 Rev. Litig. 527, 527 (2002); Melissa H. Weresh, Legal Writing: Ethical and Professional Considerations (2009). See also Mary Whisner, When Judges Scold Lawyers, 96 L. LiBr. J. 557, 558-59 (2004) (describing research strategies to find judicial opinions in which judges chastise attorneys for poor legal research and writing). 
heighten students' own awareness of their learning styles. ${ }^{78}$ Because the tools available to our students in law school may not be available to them in their legal jobs for a variety of reasons (e.g., costs or discontinuance of the tool as they know it-as with Westlaw Classic), we teach them not just alternatives but also ways to find alternatives. ${ }^{79}$ Just as law school professors need to prepare students to continue to think critically, they need to engage them with different approaches to learning. Law students have different learning styles, and instructors intend to give all of them a strong foundation for their future in practicing law. Law students may be predominantly visual, auditory, or kinesthetic learners. ${ }^{80}$ This means that law students gather and absorb information in different ways throughout the legal research process. ${ }^{81}$

As explored in the next Part, Casetext and Ravel raise similar pedagogical concerns at the same time that they help resolve them.

\section{PEdagogy and Casetext and Ravel, Two of the New "NEXT GEN" RESEARCH TOOLS}

Instruction on the next gen research tools Casetext and Ravel helps meet the pedagogical goals outlined above. Below, we first

78. Abbie DeBlasis, Brenda See, Elizabeth Usman, \& Kristin Hazelwood, Who Are Our Learners, and How Can We Teach Them More Effectively?, BELMONT UNIV., 6-29 (Dec. 6, 2013), available at http:/www.law.uky.edu/files/docs/LegalWriting/WhoAreOurLearners.pdf; Susan Herrick \& Sara Kelley Burriesci, Teaching Legal Research Online, 28 LEGAL REFERENCE SERVICES Q. 239, 240 (2009). As part of the metacognitive process, students must learn their modality in learning style. M.H. Sam Jacobson, How Law Students Absorb Information: Determining Modality in Learning Style, 8 LEGAL WRITING: J. LEGAL WRITING INST. 175, 179-80 (2002).

79. Showing students ways to find free or low-cost research alternatives rather than just identifying alternatives for them is also imperative because they may forget or become confused by a laundry list of options.

80. Thomas F. Hawk \& Amit J. Shah, Using Learning Style Instruments to Enhance Student Learning, 5 Decision ScI. J. InNovative Educ. 1 (2007); Rita Dunn \& Kenneth Dunn, Teaching Secondary Students Through Their InDIVIDUAL LEARNing STYles (1993). See also supra note 78 and accompanying text.

81. See, e.g., M. H. Sam Jacobson, How Law Students Absorb Information: Determining Modality in Learning Style, 8 LEGAL WRITING: J. LEGAL WRITING INST. 175, 179-81 (2002). 
describe Casetext and Ravel and then discuss related pedagogical considerations.

\section{A. Casetext: Resembling a Wikipedia for Case Law}

Casetext ${ }^{82}$ provides the full text of cases for free, accompanied by crowd-sourced annotations and links to secondary sources. Users can search by case caption or citation.

Anyone can annotate cases or reply to others' annotations, creating the opportunity for conversation about the law. ${ }^{83}$ "Annotation" broadly includes offering analysis (think headnotes in WestlawNext and Lexis Advance), linking to articles or other secondary sources, organizing the cases by adding tags or categorizing them (think developing KeyCite or Shepard's systems), and "upvoting" useful documents. On the transactional side, the site offers annotated contracts for those interested in insights from practitioners such as which terms have fared best in court.

New sources of free online cases seem to spring up regularly, and others, like Google Scholar, continue to evolve. ${ }^{84}$ In this everchanging landscape, Casetext's distinguishing feature is its crowdsourced annotations. ${ }^{85}$ While prior generations of legal research

82. CASETEXT, https://casetext.com/ (last visited Nov. 26, 2014).

83. The Casetext FAQs state, "Casetext users are encouraged to contribute under their real identities, so a user can see the experience and background of a particular contributor. Users also upvote and downvote contributions, and we sort them according to these votes so that you see the most valued content first." Frequently Asked Questions, CASETEXT, https://casetext.com/faq (last visited Nov. $22,2014)$.

84. The Google Scholar page represents the breadth of its case database as follows:

Currently, Google Scholar allows you to search and read published opinions of US state appellate and supreme court cases since 1950, US federal district, appellate, tax and bankruptcy courts since 1923 and US Supreme Court cases since 1791. In addition, it includes citations for cases cited by indexed opinions or journal articles which allows you to find influential cases (usually older or international) which are not yet online or publicly available. Search Tips, Content Coverage, GOOGLE ScHOLAR, http://scholar.google.com/intl/en-US/scholar/help.html\#coverage (last visited Nov. 22 2014).

85. The instructors emphasized (1) the usefulness of students creating highquality annotations, and (2) the importance of evaluating online information, i.e., 
tools (i.e., Lexis and Westlaw) offered case annotations, two components of the annotations in Casetext bring it into the next generation. First, the annotations do not issue from an unchallenged editor; rather, they emerge from a community of legal thinkers. Unfortunately, if no one contributes annotations, the tool has quite limited value. Casetext has launched "WeCite" events as components of advanced legal research classes and law student organizations. ${ }^{86}$ These events offer students and law school professors a chance to contribute annotations. During these events, students analyze and explain how various cases relate to each other, participating in the legal conversation while building content on the site. Second, Casetext offers some unique visualizations, including the "heatmap." The heatmap runs alongside the text of a judicial opinion and shows by color shade how frequently a given page of the opinion has been cited. The deeper the color, the more frequently that page has been cited. ${ }^{87}$

\section{B. Ravel: A Picture is Worth a Thousand Words ... Or Research Results}

Ravel $^{88}$ also provides the full text of cases for free. ${ }^{89}$ Like Casetext, Ravel's database of cases can be searched by case title or citation.

Ravel's distinguishing characteristic is its visual representation

information that does not necessarily have the imprimatur of reliability. See Jodi Wilson, Proceed with Extreme Caution: Citation to Wikipedia in Light of Contributor Demographics and Content Policies, 16 VAND. J. ENT. \& TECH. L. 857 (2014).

86. See, e.g., Join the WeCite Movement, CASETEXT, https://casetext.com/wecite/event (last visited Nov. 22, 2014); Min Su Chung, March 26: Launch of WeCite, SOC'Y FOR LAw, SCI. AND TECH. (SLST) (Mar. 13, 2014), http://blogs.law.columbia.edu/slst $/ \mathrm{p}=193$.

87. See Robert Ambrogi, Casetext Adds Citator, Other Features, LawSites (Mar. 26, 2014), http://www.lawsitesblog.com/2014/03/casetext-adds-citatorfeatures.html.

88. RAVEL LAW, https://www.ravellaw.com/ (last visited Nov. 22, 2014).

89. Ravel provides both free and paid access. Free access to cases from all jurisdictions is provided to those with an email address ending with .edu; if you do not have a .edu email address (i.e., you do not work or are not enrolled in an academic institution), Ravel offers free access for cases in fewer jurisdictions. 
feature indicating which cases are significant for a given point of law. ${ }^{90}$ The cases show up on the screen represented by colorful circles $^{91}$-a visual delight amidst the relatively dry presentation of other database search engines. Additionally, if a user runs a keyword search, the top seventy-five "most relevant" cases appear in a column list on the right hand side of the screen. It is not clear on what basis the algorithm conceived by Ravel to declare cases "relevant" was designed. ${ }^{92}$ The total number of results appears in light gray in the search bar.

Most of the search-results screen is comprised of a table with circles of various sizes and colors (representing cases) spread across the table, a little like a scatterplot. Hovering the cursor over a case in the right hand column causes the corresponding circle to become more visually prominent as though it is lighting up. The bottom axis of the table features a timeline of search results, showing which years produced the most cases that fall under the search terms. The user can drag and slide the bottom timeline to limit search results by date.

90. Ravel is not the first tool to use visualizations for legal research. Fastcase developed an Interactive Timeline using a similar bubble display in 2008 . Robert Ambrogi, Vision Quest: Visual Law Services are Worth a Thousand Words -and Big Money, 100 A.B.A. J. 35, 37 (May 2014). This Fastcase feature shows more important cases as larger circles, but it apparently does not show links between cases, as Ravel does. See, Cathy Underwood, Fastcase-the Next Generation of Online Legal Research, 45 ARK. LAW. 18 (Summer 2010).

91. Some students may encounter difficulties with this visualization. See Susan David DeMaine, From Disability to Usability in Online Instruction, 1-54 (Indiana University Robert H. McKinney School of Law Research Paper No. 2014-16, 2014), available at http://ssrn.com/abstract=2428420 (discussing color blindness and other limitations in using online resources) (forthcoming).

92. This problem is not unique to Ravel Law. WestlawNext uses an algorithm that in part relies on crowdsourcing-popular searches-and this feature may limit or change results. Wheeler, supra note 1 , at 361 . 


\section{Illustration $\mathrm{A}:{ }^{93}$}

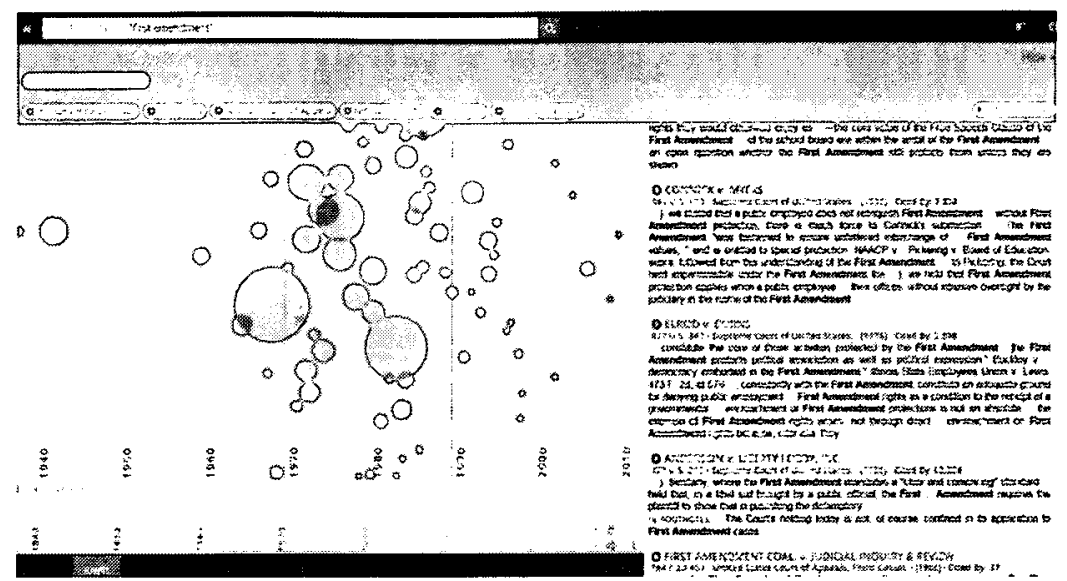

Illustration $\mathrm{B}:{ }^{94}$

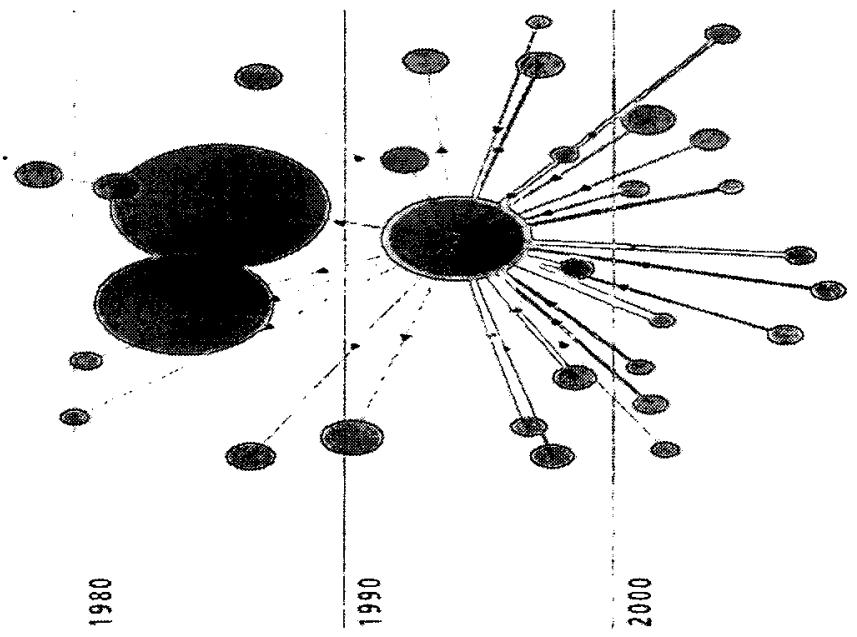

93. This screenshot was captured in August 2014.

94. This screenshot was captured in June 2014. 
When the user hovers the cursor over a circle, web-like lines connecting the circles appear. For example, if the user hovers over Case A and Case A is cited by Case B, a blue line will appear between Case A and Case B. If the user then hovers over Case B, a green line will appear between Case B and Case A indicating that Case B cited to Case A. The thicker the line, the greater the frequency of citations to or from the case. If there are no lines to or from the case/circle over which the user is hovering, that case was cited but not by cases that show up in the results. In other words, the case over which the user is hovering may be cited for a point of law other than the one the user has researched.

The user can change the display of these circles-and consequently visualization of their relationships with each otherby clicking the "filters" button just below the search bar. Filter options include "relevance" (cases most relevant to a search appear at the top of the table), "court" (Supreme Court cases appear at the top of the table), and "cluster" (cases are separated into citationbased groups, helping identify which cases are closely connected and which cases are outliers). Ravel also enables the user to limit search results by jurisdiction.

The visualization feature of Ravel distinguishes it substantially from the prior generation of legal research tools. Ravel's founders frame their goal as "contextualization," i.e., to make legal research "more intuitive, more thorough, and give people greater confidence that they're finding the cases that are best suited to their need." 95 In the past, legal researchers have relied largely on textual representations of relationships (e.g., comparing numbers of citations), but now Ravel renders these complex relationships more visible.

\section{Legal Skills Pedagogy}

As summarized in Part III, during the past 10 years, the scholarship on legal skills pedagogy has centered mainly on these interrelated areas: making students "practice-ready," metacognitive skills acquisition, information literacy (strategy, context and source

95. Ambrogi, Visual Law Services are Worth a Thousand Words-and Big Money, supra note 90. 
evaluation), using technology ethically, and teaching students with a variety of learning styles or modalities. Most scholarship addressing next gen legal research tools, including Casetext and Ravel, presents brief descriptions of the tools, ${ }^{96}$ rather than an exploration about integrating them into the curriculum. (This should not surprise; Casetext.com launched in $2013^{97}$ and Ravel in $2012,{ }^{98}$ giving scholars little time to engage with these tools inside or outside of the classroom.) We attempt to initiate a collective exploration here. Below, we explain how teaching Casetext and Ravel-our examples of next gen research tools-in the legal writing classroom address these overlapping pedagogical goals.

\section{Helping Students Become "Practice-Ready"}

With exposure to next gen research tools in their legal writing classrooms, students are learning about legal research tools they may use in law practice and therefore becoming more "practiceready." While law professors can never know with foolproof certainty what legal services technologies their students will confront after law school, in the very recent past, law professors were able to predict with reasonable certainty that most law students will come into contact with Westlaw and/or Lexis. Now, during the past few years, next gen legal research tools like Ravel and Casetext have not just made a splash in the media; they continue to develop. They are gaining traction. ${ }^{99}$

96. For perhaps the fullest example at present, see Jan Bissett \& Margi Heinen, Facing the New Normal, 92 MiCH. BAR J. 52 (2013).

97. Ambrogi, New Legal Research Site Combines Case Law with Crowdsourcing, supra note 3.

98. About Us, RAVEL LAW, https://www.ravellaw.com/about (last visited Nov. 22, 2014).

99. Both Casetext and Ravel claim their attorney user numbers are increasing. E-mail from Daniel Lewis, CEO, Ravel Law, to Susan Azyndar, author (May 16, 2014) (on file with authors); E-mail from Pablo Arredondo, Vice President, Casetext, to Susan Azyndar, author (May 19, 2014) (on file with authors). Moreover, law students at Columbia, Stanford, Nebraska, Brooklyn, Cardozo, Texas Tech, and Loyola Los Angeles have all participated in annotation exercises using Casetext, and Casetext is actively seeking additional law school classes for participation. Telephone Interview with Pablo Arredondo, Vice President, Casetext (Mar. 12, 2014). 
If one goal of a first-year legal writing course is to expose students to legal research platforms that they may encounter after law school, and these new forms of technology show no signs of disappearing or waning, then legal writing professors bear a responsibility to expose their students to these tools. Even if Ravel and Casetext themselves fold, the underlying principles of visualizations and crowd-sourcing seem to be taking hold. ${ }^{100}$ Moreover, some law students may emulate the founders of Ravel and Casetext and create new tools for lawyers.

2. Helping Students Develop Metacognitive Skills and Addressing Students' Varied Learning Styles

Ravel and Casetext look and feel different from other research platforms that have come before, but they present the same source material as the platforms that preceded them. Thus, they are wellsuited to addressing the different learning styles of law students. One goal of bringing metacognitive skills into the law school curriculum is to teach students greater awareness of their learning styles. These next gen tools offer an intriguing opportunity for students to become more aware of their learning styles through comparing their experiences using these tools and the more "traditional" Lexis Advance and WestlawNext databases.

For example, these tools might resonate with a number of students who may not have been as immediately responsive to other legal research tools (including the classic print secondary sources). Exposure to a variety of tools-i.e., teaching students that if something is not working for them, perhaps they apply their fundamental research skills to something that reflects their best learning style-can only give students more opportunities to succeed.

Take Ravel for example. Law school professors must constantly strive to find ways to reach all types of learners, including visual learners. ${ }^{101}$ Robert Ambrogi describes an increase in visualization

100. See Ambrogi, New Legal Research Site Combines Case Law with Crowdsourcing, supra note 3; Ambrogi, Visual Law Services are Worth a Thousand Words-and Big Money, supra note 90.

101. We recommend several ways to incorporate these tools in law school classrooms below. 
tools for legal research, calling Ravel "useful and intuitive." 102 In particular, Ambrogi claims that visualizations help legal researchers identify the most important cases and know when to stop research. ${ }^{103}$ This assessment leads us to consider categories of learning styles, specifically the visual learner. Some scholars claim that many law students learn visually, and further, that visual learners make up an increasing percentage of the law student body. ${ }^{104}$ Meanwhile, others caution that an increase in visual experiences (television, games) does not equate with visual learning styles or particular expertise in visual literacy. ${ }^{105}$ Moreover, those who learn visually may struggle in law school more than other types of learners. ${ }^{106}$ Ravel, then, not only draws on entering law students' common experiences with technology but also may help those students who may perform more poorly in the ordinarily text-dominated world of legal research.

3. Enhancing the Teaching of Information Literacy: Strategy, Context, and Source Evaluation

\section{Strategy}

Today, just as not all print sources serve the same purpose, not all electronic sources do either. Law students have many more choices among legal research media today than they did just twenty years ago. Law instructors need to continue to point out the pros and cons of using one electronic platform versus another for different tasks. Casetext, Ravel, and other next gen tools should be brought into that conversation.

102. Ambrogi, supra note 3. For another example of technology that helps students (and lawyers) visualize their arguments, see Allison D. Martin, A Picture is Worth a Thousand Words: How Wordle ${ }^{T M}$ Can Help Legal Writers, 9 J. Ass'N LEGAl Writing Dirs. 139 (2009).

103. Id.

104. M. H. Sam Jacobson, A Primer on Learning Styles: Reaching Every Student, 25 Seattle U. L. Rev. 139, 151-52 (2001); M. H. Sam Jacobson, Learning Styles and Lawyering: Using Learning Theory to Organize Thinking and Writing, 2 J. Ass'N Legal WriTING Dirs. 27, 34 (2004).

105. Eva Brumberger, Visual Literacy and the Digital Native: An Examination of the Millennial Learner, $30 \mathrm{~J}$. VISUAL LiTERACY 19, 44 (2011).

106. Jacobson, A Primer on Learning Styles, supra note 104, at 152. 
By continuing to teach the latest low-cost and free online legal research alternatives, teachers reinforce students' skills in shopping around for the best price for their needs. Familiarity with the variety of available tools and their cost structures will help our students make better, more informed research spending choices after graduation - a skill legal employers value highly. ${ }^{107}$

\section{Context}

When introducing Casetext and Ravel, law professors can focus on teaching students that the process of legal research is the same, regardless of its fancy new technological form. That the legal writing course goal to teach students the basic principles of legal research will always remain the same and might at first blush seem antithetical to introducing a new legal research technology into the classroom. But as stated earlier, those who teach legal writing and research emphasize the sameness of the legal research process: issue spotting, identifying key search terms, and looking at secondary sources. Emphasis on this process gives students something fixed to rely on regardless of whether their research takes them online, to print material, or to some as-yet-created research context.

Yet this firmly established approach might lead many to conclude that introducing new legal research platforms is not important. We propose just the opposite. Legal research technology is entering a new era, as the Westlaw and Lexis monopoly wanes. Law students are very likely to be introduced to new technologies at a quicker pace than any other generation of law students that has come before them. After all, WestlawNext, Lexis Advance, Casetext, and Ravel were all launched within the last four years, and they comprise just a few of the new legal research tools. ${ }^{108}$ If

107. See supra notes 57-58 and accompanying text. But see Sarah Gotschall, Teaching Cost-Effective Research Skills: Have We Overemphasized Its Importance?, 29 LEGAL REFERENCE SERVs. Q. 149 (2010) (arguing that the need to teach cost-effective research should be limited to law schools who send a large percentage of students to work in large law firms).

108. In 2011, JustCite introduced a tool called the Precedent Map, which presents a visual image of case relationships. New JustCite Precedent Visualization Tool, SMU LAW LiBRARY (Feb. 24, 2011), https://smulawlib.wordpress.com/201 1/02/24/new-justcite-precedent-visualisation- 
history is any indicator at all, every technology will promise to be quicker, more efficient, and more innovative. The promise is only realized when and if the user knows how to expertly use the technology.

Part of the law school professor's job is to demonstrate to students that the more things change, the more they stay the same-i.e., teach students to connect prior learning to new contexts. In short, developing a basic research strategy remains vital, ${ }^{109}$ as does the ability to apply those strategies to new tools. Law instructors will have more credibility and influence, and their lessons more impact, if they can show students precisely how to transfer their fundamental research strategies to next gen research tools.

\section{Source Evaluation and Ethics Related to the Newest Technology}

A crowd-sourced research tool would seem to be the ideal platform for initiating the teaching of legal research to students who have known social media their entire educational lives. Casetext's approach to filling in the editorial details embraces a collaborative mindset and permits students to become active participants in the legal community. While Casetext may seem to offer simply what Westlaw and Lexis have offered for years, a bank of case law bolstered by editorial materials like headnotes, the crowd-sourced nature of Casetext's editorial content signals a significant change from older models. Casetext makes the legal research process less solitary and more social. ${ }^{110}$ Our students come to law school with an increasingly social mindset. ${ }^{11}$ As a result, the

tool/. Similarly, Fastcase, a subscription service often offered through bar associations, now offers a "patent-pending Interactive Timeline" designed to help researchers "see" relationships between cases. What is Fastcase? FastCase, http://www.fastcase.com/whatisfastcase/ (last visited Nov. 22, 2014). Mootus.com, a site that supports crowd-sourced answers to questions, launched in March of 2013. Lucy Burton, Technology: Tweet Dreams, THE LAWYER (Mar. 3, 2014), http://www.thelawyer.com/analysis/the-lawyer-management/managementanalysis/technology-tweet-dreams/3016425.article.

109. See supra notes 54-55 and accompanying text.

110. Ambrogi, 2 New Websites Offer Platform for Crowdsourced Legal Research, supra note 11, at 28.

111. Stephen M. Johnson, Teaching for Tomorrow: Utilizing Technology to 
call for collaborative learning grows increasingly louder. ${ }^{112}$ The crowd-sourcing premise of Casetext meets that call. ${ }^{113}$

A legal research tool that invites critical review of source trustworthiness places critical evaluation of sources front and center in a law student's research process, and provides a teaching moment for ethical considerations in the use of new technology. When instructors demonstrate that Casetext includes annotations created by peer authors, students are reminded to pause to critically consider the trustworthiness of the source, seeming more inclined to corroborate what they learn through Casetext. Alternatively, law students tend to view commercial database headnotes as presumptively authoritative, effectively encouraging them to bypass the evaluative step emphasized by legal research scholars as so critical. The difference between Casetext's user-generated tags and the indexing available on WestlawNext and Lexis Advance provides another useful counterpoint. Indexing captures synonyms and other word variations; user-generated tags do not. ${ }^{114}$ For example, the user-generated tags for Citizens United v. F.E.C. in Casetext include both "De Minimus" and "De Minimus Standard." 115 Examining this difference should encourage students to think about context and how legal information is organized.

In the following Part, we explain how, with all of these pedagogical considerations in mind, we introduced these next gen

Implement the Reforms of MacCrate, Carnegie, and Best Practices, 92 NEB. L. REV. 46, 53-57 (2013).

112. See, e.g., id. at 56.

113. Some scholars have discussed using wikis as a tool for collaborative learning. E.g., Feng Su \& Chris Beaumont, Evaluating the Use of Wiki For Collaborative Learning, 47 InNOVATIONS Educ. \& TEACHING INT'L 417 (2010); Mary E. Engstrom \& Dusty Jewett, Collaborative Learning the Wiki Way, 49 TECH TRENDS 12 (2005). Some recognize that wiki-type technology contributes to collaborative knowledge building. Ulrike Cress \& Joachim Kimmerle, $A$ Systemic and Cognitive View on Collaborative Knowledge Building with Wikis, 3 INT'L J. COMPUTER-SuPPORTED COllaborative LEARning 105 (2008). While Casetext is not a wiki created within one classroom, it draws on collaborative knowledge building principles. Users can add questions and answer questions from others, which would bolster the degree of collaboration involved.

114. Alireza Noruzi, Editorial, Folksonomies: Why Do We Need Controlled Vocabulary?, 4 Webology (June 2007),

https://www.mysciencework.com/publication/read/2475168/folksonomies-whydo-we-need-controlled-vocabulary\#page-1.

115. See Citizens United v. F.E.C., 558 U.S. 310 (2010). 
research tools into the legal writing classroom, and we offer some ideas for future integration of these tools in the first-year legal writing curriculum.

\section{Teaching NeXT Gen Research ToOls: A Teaching AND ASSESSMENT PILOT MODULE, AND IDEAS FOR MOVING FORWARD}

Law school professors who agree that the next gen tools Ravel and Casetext merit a place in the legal skills curriculum have little scholarship to consult about how those tools should be taught. With the pedagogical goals described in Part III above as drivers, the authors developed a pilot teaching and assessment module and implemented it in a first-year legal writing classroom at The Ohio State University's Moritz College of Law ("Moritz Law"). ${ }^{116}$

\section{A. A Pilot Attempt at Teaching Next Gen Research Tools}

In the Spring 2014 semester, we designed and implemented a pilot teaching and assessment module to (i) ascertain our students' knowledge of, and exposure to, next gen research tools for the purpose of informing our teaching in the course and (ii) expose our students to, and teach them about, those tools. The module was designed for a second-semester IL legal writing course in which the professor focuses on persuasive writing. The module is simple in structure: (1) a questionnaire, (2) a joint in-class presentation by a reference librarian who also teaches LAW classes and the legal writing professor, and (3) a follow-up assessment and reflection survey.

116. By way of background, the following is a brief overview of The Ohio State University Moritz College of Law's ("Moritz Law") first-year legal writing curriculum: At Moritz Law, first-year students are required to take two semesters of Legal Analysis and Writing (LAW), referred to as LAW 1 and LAW 2. LAW 1 focuses on predictive legal writing and LAW 2 on persuasive legal writing. LAW 1 is taught in the fall and LAW 2 in the spring. Both courses incorporate legal research and professionalism learning goals. Students are assigned one professor for LAW 1 and then take a different professor for LAW 2. LAW professors are drawn from many quarters within the law school: clinical track professors, tenured professors, law librarians, tenured professors, and others. See Understanding the importance of writing clearly and effectively, THE OHIO STATE UNIVERSITY, MORITZ COLLEGE OF LAw, http://moritzlaw.osu.edu/studies/legalwriting/ (last visited Nov. 22, 2014). 


\section{Questionnaire}

Several days before the start of the Spring semester, Professor Katrina Lee ("Professor Lee") distributed a short questionnaire ${ }^{117}$ to her eighteen enrolled legal writing students ${ }^{118}$ (the "Questionnaire"). The purpose of the questionnaire was to learn more about students' research and writing backgrounds which could impact the professor's teaching. It included questions about students' experiences with writing and this question about research tools:

Have you heard of Casetext? Of Ravel Law? Of any other next gen research tools? For each that you have heard of, please answer these follow-up questions: Have you used it? If yes, briefly describe for what purpose you used it. Did you enjoy using it? How did your experience using it compare to your experiences using Lexis Advance and WestlawNext? Explain.

Of the eighteen students, only one had prior knowledge of Ravel, and no one had knowledge of Casetext. ${ }^{119}$ The student who had knowledge of Ravel did not know how it worked.

The course began with no mention of Ravel or Casetext. Soon, the students began research on a pre-trial motion that was their major persuasive writing assignment of the semester. Professor Lee required her students to submit a research $\log$. In the research log, the students were required to indicate what research platforms they had used. Not surprisingly, since nearly all had never heard of

117. The Questionnaire was posted in Word format on the Westlaw TWEN site for the course. Students were advised that the Questionnaire answers would not be graded but they were required to complete the Questionnaire. Students typed in their answers and then submitted their answers on TWEN. The Questionnaire included questions about what they had learned in LAW 1 and what they hoped to learn in LAW 2.

118. This pilot focused on only one class involving a small group of students. Despite this small sample size, we anticipate that other similar classroom activities will yield similar student comments and similar learning opportunities.

119. The authors welcome inquiries from other professors interested in seeing the complete set of answers to the Questionnaire question about Casetext and Ravel. 
either Ravel or Casetext, the students indicated on their logs that they had used Westlaw, Lexis, Bloomberg Law, Google, and the occasional print source for their research, ${ }^{120}$ and none indicated research on a next gen research platform like Ravel or Casetext.

\section{Preparation by the Instructors for the Class Session Devoted to Casetext and Ravel}

To prepare for the class module dedicated to Casetext and Ravel, Professor Lee and Professor Mattson (a reference librarian) ${ }^{121}$ (referred to jointly as the "instructors") met to discuss the major issue that the students were researching for the assigned pre-trial motion. The students had already done extensive research on the problem, and they had participated in many classroom discussions about the research. So, the students had some fairly solid context concerning jurisdiction, scope of case coverage, and vocabulary.

The instructors first tried to figure out if the authorities the students needed for the motion could be found on the next gen research platforms. If key cases were not available due to limitations in coverage, the instructors would have to abandon the module altogether or adjust their teaching strategy accordingly. The key cases were indeed available on both Ravel and Casetext.

The instructors also discussed how the module could help develop metacognitive skills and flexible research strategies. They wanted to build in reflection. They designed a debrief session in which they led discussion about how those key cases appeared in "traditional" print and electronic resources and then transitioned into a compare-and-contrast debrief exploring and reflecting on the search functionality of the next gen platforms.

During class preparation, using Ravel and Casetext, the instructors checked and reviewed all key cases for the research project. Through this review, the instructors discovered that the Casetext search results on the assignment topic were not heavily annotated. The librarian added annotations before class, drawing

120. As it happens at many law school campuses across the country, all $1 \mathrm{~L}$ students at Moritz Law are provided free access to Westlaw, LexisNexis, and Bloomberg at the beginning of the academic year.

121. Both are authors of this article. 
connections between cases across jurisdictions and adding information about related secondary sources. Similarly, when working with Ravel before class, the instructors constructed the most fruitful Ravel search string ${ }^{122}$ by testing a number of search strings.

\section{Implementation: Class Session}

About halfway through the semester, the students had made substantial progress on the research for their major persuasive writing assignment and turned in their research logs. At this point, the instructors engaged in an interactive, approximately 40-minute, presentation and exercise with the students about next gen research tools. The instructors started by discussing the purpose of exposure to these new tools: the students should work towards developing skills versatility among various databases for legal work after law school; and the students would find that understanding these newest tools would help make them stronger researchers. They discussed briefly how Ravel works and how Casetext works, reminding the students along the way of the ethical implications of learning the limitations of research tools.

The librarian then gave an overview of the capabilities, scope, and limitations of each. Rather than run a "cold" demonstration using new research material, she engaged the students in an exercise related to the project in which they were already immersed. Guided by the instructors, the students brainstormed search terms related to the motion assignment and typed them into Ravel. Audible exclamations of excitement filled the room when students saw the different visual representations of research results appear on their laptop screen on Ravel. Thus, almost instantly, students reacted excitedly to these alternative ways of working with legal information.

The instructors also demonstrated a potential difference between database coverage and the level of the researcher's access to the

122. Because the research topic involved social media and issues related to social media have not regularly been before courts, using a search string describing social media in a variety of ways was necessary. The teachers' search ultimately required using the terms "social media" and "social network" as well as specific social media platforms like MySpace and Facebook. 
database. Depending on the level of access for which a user has paid, a researcher might not have access to the database's entire contents. This led to a discussion of the significance of recognizing when search results raise flags and should be further explored. As mentioned earlier, Ravel provides free access to its entire database for those with email addresses ending with .edu. ${ }^{123}$ For other users, access to database contents can vary depending on price paid. The circles or bubbles in Ravel do not readily point out limitations in coverage brought about by varying levels of coverage. In class, the librarian informed students she logged in before class using her .edu email address and ran a search, and she invited the students to do the same. Ravel's visual interface made it immediately clear to students who had not logged in for full database access that something was different about their search and their searches resulted in far fewer circles (i.e., cases). The instructors explained that full database access retrieves federal district court cases, which were critical to the students' research. The instructors were thus able to demonstrate that if students did not take the time to learn a database's coverage (especially so early in their legal careers) and the extent of their access to it, they would be far more likely to conclude mistakenly that the meager search results obtained encompassed all the results possible, perhaps causing them to miss key cases.

When Casetext was discussed, students grasped immediately the crowdsourcing, Wikipedia-like concept of the Casetext platform and asked questions about how much they could "trust" the annotations on Casetext, encouraging students to engage in source evaluation. ${ }^{124}$ The lack of a high number of annotations provided an opportunity for a "teachable moment." Students were entertained and quite interested to see the librarian's name accompanying the few annotations to a key case. To reinforce students' confidence in

123. Choose Your Plan, RAvel LAw, https://www.com/features (last visited Nov. 22, 2014).

124. The authors note they did not suggest to students that crowd-sourced annotations are inherently reliable. Instead, they emphasized (1) the value of students creating high-quality annotations for reputational purposes, and (2) the importance of evaluating online information, i.e., information that does not necessarily have the imprimatur of reliability. See Jodi Wilson, Proceed with Extreme Caution: Citation to Wikipedia in Light of Contributor Demographics and Content Policies, 16 VAND. J. ENT. \& TeCH. L. 857 (2014). 
their own research skills, the librarian noted that students' knowledge of this area of law far outweighed hers since they had worked on the project already for several weeks; they could provide valuable insights for future researchers in this area by adding their own Casetext annotations. ${ }^{125}$

The "trial and error" preparation that the instructors engaged in also resulted in many teachable moments with connections to the instructors' pedagogical goals. For example, one teachable moment concerned the "context" prong of information literacy. The instructors asked students to think critically about why they did not necessarily get the results they expected. They responded that perhaps the search terms used were problematic. This impediment gave students a chance to propose alternative search terms and then speculate as to why various searches produced varying results. In other words, students developed the legal context for their problem. Additionally, though we had already told students which reporters were included in Casetext, this exercise prompted them to think about the difference between reported and unreported cases from a research perspective. ${ }^{126}$ The students also quickly became attuned to the imperative that they understand where these next gen tools source content and how decisions about what to include in the databases are made. Within a 40-minute session, the students were suddenly engaged in discussions about context and considering how next gen tools might best fit into a legal research strategy.

The instructors explained the process of working backwards, creating a search string that would produce particular cases and talked about lessons learned. For example, sometimes attorneys research new areas where vocabulary is not settled. "Social media" in one judicial opinion might be "social networking" or even "online communities" in another. The instructors were able to reinforce that different online databases may function differently,

125. Some instructors may be understandably reluctant to require their students to create Casetext annotations. Some students lack confidence in their legal skills, and the annotations are a public record anyone, including potential future employers, can see.

126. Casetext describes its coverage in terms of reporters rather than jurisdictions. Consequently, it appears to only include reported (i.e., published) cases. This may prove problematic if Casetext includes state cases given that some states (e.g., Ohio) publish online using vendor neutral citation. 
and it is the responsible attorney's job to be able to use online tools competently and discover how they operate in order to truly know whether their searches produce comprehensive results. In other words, in part because of their earlier research using Westlaw, Lexis, and Bloomberg, students developed a stronger understanding of legal context as well as of how best to ethically use these research tools. They also at least implicitly acknowledged the value of the classification systems available in traditional platforms. For example, the West key number system groups cases on similar points of law without regard to different judicial wording. ${ }^{127}$

\section{Assessment and Reflection Questions ${ }^{128}$}

In the next class, students were provided with a series of questions (the "survey") related to their class experience with the next gen research tools. For about 20 minutes, students responded anonymously to the questions using Google Forms online. In developing the survey, we had a couple of primary goals. With an eye towards helping students develop their metacognitive skills, we wanted to give them an opportunity to reflect further on the new research tools they had been introduced to. We also wanted to assess what they had learned from the class session on Casetext and Ravel.

Of the eighteen students in the class, seventeen responded to the survey. ${ }^{129}$ The students, with a couple of exceptions, were very positive about their exposure to the new research tools, and they made thoughtful comments about what they perceived to be the benefits and drawbacks of the new tools. Their answers provided insights into how they view both the "old" platforms of Lexis Advance and WestlawNext and these next gen tools, Ravel and Casetext, as well as how they view legal research generally.

127. For an explanation of both the West and Lexis classification systems, see Susan Nevelow Mart, The Case for Curation: The Relevance of Digest and Citator Results in Westlaw and Lexis, 32 Legal RefERENCE SERVS. Q. 13 (2013).

128. The full list of the questions provided to students is provided in the Appendix.

129. Two students were absent from class when the survey was distributed. One of those two students filled out the survey outside of class. 
A majority of students responded that they were likely or very likely to use the next gen research tools again.

Students mostly responded positively to the questions, "How likely are you to hop onto the Ravel website and practice using it in the next six months?" and "How likely are you to log onto the Casetext website and practice using it in the next six months?" The multiple choice responses were: "Very likely," "Likely," "Slim chance," and "Not a chance." In response, the vast majority of students indicated that they intended to use the tools again. Seventy percent of the students responded that they were "very likely" or "likely" to use Ravel in the next six months, and 58 percent of the students responded that they were "very likely" or "likely" to use Casetext in the next six months.

Students generally equated Ravel with "visual" and Casetext with annotations.

Student comments were supportive of visual learning and collaboration. Comments about Ravel included, "You can use Ravel to visually see connections between cases," "Useful way to view case law, i.e., in graphic view," and "it's great for visualizing and interacting with cases, and for seeing the factors laid out in graphic form." Student comments about Casetext included "Casetext is the wikipedia [sic] of caselaw," "Casetext sounds fascinating. I like that it's crowdsourced information on cases," "Being able to read user submitted comments is a huge benefit," and "Casetext allows others to annotate the cases."

Westlaw and Lexis remain student favorites.

Question No. 14 asked, "What online legal research tool do you find easiest to use? (This can include Ravel, Casetext, BloombergLaw, Westlaw, Lexis, or any other tool you use.) Why?" Students responded overwhelmingly that Westlaw or Lexis was the easiest online research tool to use. However, when asked why, they often commented because it was the one they use the most or were most familiar with. One student, for instance, answered, "Lexis, because of familiarity. No other reason really." Another responded, 
"Westlaw, primarily because it's what I've used most." Others had reasons related to their perception of the search capabilities of the respective platforms. One student responded, "Westlaw, the speed and sorting options seemingly make it superior to the others that I have used." Another liked Lexis for its Shepardizing function. Because students seemed entrenched in the familiar, it is important to expose students to alternative research tools so that they can develop appropriate research strategies sensitive to professionalism issues, such as costs.

Students' reservations about the next gen research tools mostly related to reliability or completeness of available materials rather than navigation or user-friendliness.

Regarding Casetext, one student commented, "I think the biggest thing is that the annotations provided by the community could be wrong or misguided, and that could be an issue." However, another student had a more positive take on the same issue, "No reservations with the understanding that the comments are opinion and should not be interpreted as authoritative statements about the case. Relying too heavily on unverified submission may lead me in the wrong direction." Several students pointed out the "incomplete" nature of Ravel. One student even compared Ravel to Lexis and Westlaw: "The incomplete nature of the database compared with Lexis or Westlaw." Another commented, "I am concerned that there may not be the total number of cases that I would need to conduct thorough research on a subject." Still another commented, "I had reservations about whether all the material I would need to search is available as it is a relatively new tool." These comments demonstrate that students attended to source evaluation, although they seemed to implicitly accept Westlaw and Lexis as authoritative.

Students appreciated the exposure to these new tools that they had not even heard of, and many see the new tools as helpful supplements.

Students remarked that they were glad to know about these tools. One student commented, "I think it is always good to be right at the edge of the curve in terms of what is the newest technology." 
Another responded, "I think it's helpful to be exposed to alternate forms of research and how we can utilize them. It's a nice way to supplement other research tools." Another commented that the new tools might be useful when she reached an impasse in her research: "... they can provide efficient alternative tools to my general research, especially if I were to get stuck." Here, students recognized the potential value of next gen tools as part of a solid legal research strategy.

B. Takeaways and Ideas for Moving Forward with Teaching "Next Gen" Research Tools

We gathered these lessons from our teaching and assessment module: Our students were not likely to seek out new research tools on their own; thus, if not for their law school professor introducing these next gen tools to them, they may not have used these tools until required to do so in an employment situation. Also, our students tended to use the tools they were introduced to in law school orientation or in their law school legal writing class, which they explored on their own. They stuck to using Westlaw and Lexis mainly out of habit and because these are the tools they know best or the only tools they know. They expressed a reluctance to seek out other research platforms once they became familiar with one set of research tools.

We also learned from this experience that our students are drawn to the visualization tools of Ravel and instantly had skepticism about crowd-sourcing on Casetext. This suggests that these tools may provide outstanding teaching opportunities. For example, the circles on Ravel could inform an entire session on context in research. In the alternative, Casetext's annotation or a lack thereof highlight the need for source evaluation.

To deepen the lessons about information literacy-strategy, context, and source evaluation-and ethical use of new research technologies, we propose a few ideas for future teaching pilots.

\section{Assign Comparative Searches}

Students could compare the outcomes and experiences of using different research tools for the same project. For example, a legal writing professor could split students into Ravel and Casetext 
groups, and have all students research the same topic. This would help reinforce lessons about strategy, encouraging students to think about which tools most closely suit which purposes. The class design would have to take into account respective coverage on the two tools. In another variation, the professor could split students into Ravel or Casetext groups, on one hand, and Westlaw or Lexis groups, on the other hand. This approach could also reinforce the concept of source evaluation, especially if the assignment involved conflicting information.

\section{Use Only Ravel or Only Casetext for the First Part of the Semester}

The more adventurous professor might try limiting the research tools used by students to only Ravel or only Casetext for part of a semester. While this could be tricky given the coverage issues already discussed, this approach would open up numerous opportunities to discuss strategy, context, and source evaluation. ${ }^{130}$ We would recommend this approach only after students have developed basic legal information literacy skills. By limiting part of the semester to one or both of these next gen tools, students will have to think more strategically about database content coverage. They will also have an opportunity to learn an online resource in great depth, a chance not available when working with the deep databases of WestlawNext and Lexis Advance. This experience may also give them a chance to make recommendations to vendors to improve products. Moreover, this option perhaps most directly links up to metacognitive skills, especially if students are required to write about the process of learning Ravel or Casetext and then about how that process differed from learning Westlaw or Lexis.

130. Carrie W. Teitcher describes a similar exercise involving competing groups of students working on the same problem, with some groups limited to Westlaw or LexisNexis and others limited to Google. This exercise emphasized the need for context (developing a legal vocabulary) as well as the advantages and disadvantages of each type of source. Teitcher proposes one additional course tool, a Legal Writing and Research Support Page on TWEN for the entire first-year class, which included material on free online research. Teitcher, supra note 55 , at 566. 


\section{Assess Casetext or Ravel Strengths and Weaknesses through a Research Plan}

On a smaller scale of using only one next gen research tool, students could begin a research problem using only Casetext or Ravel to acquire as much information as possible. Then, based on their results, they could reflect on what questions remain unanswered and prepare a follow-up research plan based on any gaps in their research resulting from using only these next gen tools. This kind of class would require students to focus on the legal research process and to think about using sources strategically and ethically (i.e., cost-effectively).

\section{Repeat the Pilot with More Time Allotted}

Our session with next gen tools took less than an hour of class time. A legal writing professor could easily devote more class time to letting students explore the annotations on Casetext and figure out the bubbles in Ravel or design an out of class assignment encouraging this exploration.

\section{Illustrate Common Law Principles with Ravel}

Because Ravel provides visualization of relationships between cases, showing students a case map will help reinforce how the common law develops over time. This exercise could be especially helpful in $1 \mathrm{~L}$ and LLM classrooms.

\section{Demonstrate Alternative Ways to Outline Legal Topics}

Some students may struggle with text-based outlining methods. ${ }^{131}$ Seeing how Ravel depicts case relationships may inspire these students to find more effective ways of organizing cases, whether for a writing project or for exam preparation.

131. See Jacobson, A Primer on Learning Styles, supra note 104, at 152, and Jacobson, Learning Styles and Lawyering, supra note 104, at 34; see also Jennifer Jolly-Ryan, Disabilities to Exceptional Abilities: Law Students with Disabilities, Nontraditional Learners, and the Law Teacher as a Learner, 6 NEV. L.J. 116, 129 (2005). 


\section{CONCLUSION}

Teaching the next gen research tools serves a host of pedagogical goals that have been discussed and analyzed extensively over the past decade. Through students' use of these tools, lessons about information literacy - strategy, source evaluation, and context-are reinforced. Metacognitive skills and the ability to spot ethical issues are strengthened. Also, exposure to a new way of looking at research results is alone a meaningful experience for our students, who will need to be nimble in a fastevolving research landscape. In just less than a year of law school, many of our students became firmly attached to one research platform. In this fast-paced technological age, law students must be more nimble, and attention to metacognition is a crucial component of meeting that goal. Legal writing professors and other law professors can play a crucial part in training our students in readiness for changing technological realities as well as the attendant ethical challenges of this evolution. Legal skills professors should incorporate the next gen research platforms in their curriculum; embracing these new research tools will lead to pedagogical refinements and further exploration by students and faculty alike of the benefits and drawbacks of these next gen tools of the moment. 


\section{Appendix}

Assessment and Reflection Questions Provided to Students on March 7, 2014

1. Before last Friday's class session, had you ever heard of Ravel (other than from your LAW 2 professor)? (Students could click on "Yes" or "No.")

2. Before last Friday's class session, had you ever heard of Casetext (other than from your LAW 2 professor)? (Students could click on "Yes" or "No.")

3. What did you learn about Ravel during class last week?

4. What did you learn about Casetext during class last week?

5. Have you tried using Ravel outside of class? (Students could click on "Yes" or "No.")

6. Have you tried using Casetext outside of class? (Students could click on "Yes" or "No.")

7. How likely are you to hop onto the Ravel website and practice using it in the next six months? (Students could click on "Very likely," "Likely", "Slim chance," or "Not a chance.")

8. How likely are you to log onto the Casetext website and practice using it in the next six months? (Students could click on "Very likely," "Likely", "Slim chance," or "Not a chance.")

9. Describe your understanding of what Ravel does.

10. Describe your understanding of what Casetext does.

11. What did you like about Ravel (if anything)?

12. What did you like about Casetext (if anything)?

13. Describe any reservations you have about using Ravel.

14. Describe any reservations you have about using Casetext.

15. Do you expect that you will need to know how to use Ravel and Casetext in your law practice after law school?

16. What online legal research tool do you find easiest to use? (This can include Ravel, Casetext, BloombergLaw, Westlaw, Lexis, or any other tool you use.) Why?

17. Are you glad for the exposure to Ravel and Casetext in LAW 2? Explain. 